\title{
Analisis Kapasitas Sistem Saluran Drainase Di Perumahan Dramaga Cantik 2 Kabupaten Bogor
}

(Analysis of Drainage Channel System Capacity in Dramaga Cantik 2 Residence Bogor Regency)

\author{
Muhammad Raka Qintana ${ }^{1}$, Nora Herdiana Pandjaitan ${ }^{1 *}$, dan Sutoyo ${ }^{1}$ \\ ${ }^{1}$ Departemen Teknik Sipil dan Lingkungan, Fakultas Teknologi Pertanian, Institut Pertanian Bogor. \\ Jl. Raya Dramaga, Kampus IPB Dramaga, PO BOX 220, Bogor, Jawa Barat Indonesia \\ *Penulis korespondensi: norahp@apps.ipb.ac.id
}

Diterima: 27 Maret 2019

Disetujui: 22 April 2019

\begin{abstract}
Bogor is a city with a high rainfall. Bogor has the average monthly rainfall of $267.3 \mathrm{~mm}$ with an average of 16 days of rain per month. This research purpose are to identify the condition of the existing drainage channels and to analyze the magnitude of runoff discharge compliance with existing drainage channels capacity. This research was conducted from May to August 2017 in Dramaga Cantik 2, Bogor, West Java, were analyzed using EPA SWMM 5.1. Based on the rainfall data processing of Dramaga area, Bogor, this research used distribution method of Log Pearson III. The result showed that maximum rainfall was $129.722 \mathrm{~mm}$. The result of EPA SWMM 5.1. simulation showed that drainage channel capacity could accommodate the runoff, but channel C24 was overflow. It was suggested to improved channel width to $0.42 \mathrm{~m}$ with cost of $R p$ 2,368,393.00.
\end{abstract}

Key words: drainage channel capacity, EPA SWMM 5.1, rainfall, runoff

\section{PENDAHULUAN}

Cuaca merupakan penentu aktifitas keseharian manusia pada umunya. Tak dapat dipungkiri bahwa cuaca yang tidak stabil dapat mengganggu kegiatan seharihari. Salah satu cuaca yang menjadi faktor penentu kehidupan adalah hujan. Kota dengan curah hujan tinggi mewajibkan penduduknya memperhatikan kemampuan pengendalian air hujan diantaranya dengan menggunakan saluran drainase.

Bogor merupakan kota dengan curah hujan yang tinggi. Menurut Stasiun Klimatologi Kelas I Dramaga, Kabupaten Bogor, rata-rata curah hujan bulanan per tahun yaitu sebesar 263-356 mm. Data statistik tersebut menunjukkan bahwa Bogor membutuhkan daerah resapan air yang cukup dan memadai. Untuk itu dibutuhkan sistem drainase yang baik agar tidak terjadi kelebihan air limpasan.

Meningkatnya intensitas air hujan pada musim hujan dapat mengakibatkan meningkatnya bencana banjir di beberapa daerah di Indonesia. Menurut Widiati (2008), risiko bahaya dan kerugian dapat dikurangi dengan menerapkan manajemen risiko bencana. Salah satu caranya adalah dengan mengoptimalkan saluran drainase untuk mengurangi limpasan dan menanggulangi potensi terjadinya banjir. Limpasan dan genangan akibat hujan dapat menyebabkan kerusakan konstruksi bila tidak ditanggulangi dengan tindakan preventif maupun adaptif (Ihsan dan Setiawan 2014).

Sistem drainase adalah rangkaian kegiatan yang membentuk upaya 
pengaliran air, baik air permukaan (limpasan/run off), maupun air tanah (underground water) dari suatu daerah atau kawasan. Sistem drainase merupakan bagian penting pada suatu kawasan perumahan. Suatu kawasan perumahan yang tertata dengan baik haruslah juga diikuti dengan penataan sistem drainase yang berfungsi untuk mengurangi atau membuang kelebihan air dari suatu kawasan atau lahan sehingga tidak menimbulkan genangan air yang dapat menganggu aktivitas masyarakat dan bahkan dapat menimbulkan kerugian sosial ekonomi terutama yang menyangkut aspek-aspek kesehatan lingkungan permukiman (Fairizi 2015). Oleh karena itu, penelitian ini dilakukan di perumahan Dramaga Cantik 2 untuk mengevaluasi kesesuaian sistem drainase dengan limpasan yang terjadi.

$$
\text { Permasalahan limpasan di }
$$

perkotaan khususnya pada kawasan perumahan dapat dianalisis menggunakan model EPA SWMM 5.1. EPA SWMM yang merupakan model yang digunakan untuk merencanakan dimensi saluran yang mampu mengalirkan debit air yang ada, serta merencanakan dimensi saluran dengan cara mengiterasi dimensi saluran dalam perogram tersebut hingga saluran tersebut dapat mengalirkan debit air tanpa terjadi limpasan (Fairizi 2015). Penelitian ini bertujuan untuk mengidentifikasi kondisi saluran drainase yang ada serta menganalisis kesesuaian besarnya debit limpasan dengan kapasitas saluran drainase yang ada.

\section{METODOLOGI}

Prosedur penelitian terdiri dari beberapa tahapan berupa studi pustaka, pengumpulan, pengolahan dan analisis data. Prosedur penelitian secara rinci disajikan dalam bagan alir prosedur penelitian pada Gambar 1 .

Penelitian analisis saluran drainase pada perumahan Dramaga Cantik 2 ini dilakukan dengan langkah-langkah sebagai berikut:

1. Studi pustaka

Metode studi pustaka dilakukan untuk mendapatkan informasi yang dibutuhkan dalam menganalisis permasalahan. Studi pustaka dapat diperoleh dari publikasi ilmiah atau jurnal, laporan penelitian yang berkaitan dengan permasalahan, dan buku-buku yang menerangkan tentang aspek yang digunakan dalam menganalisis permasalahan.

2. Pengumpulan data

Data yang dikumpulkan berupa data primer dan data sekunder. Data primer diperoleh dengan pengukuran langsung di lokasi penelitian. Data primer yang dibutuhkan adalah kondisi jaringan drainase eksisting yang meliputi jenis saluran, dimensi saluran, elevasi saluran, dan batas daerah tangkapan air di setiap subcatchment. Pengukuran data primer dilakukan dengan menggunakan alat theodolite, target rod, dan kompas. Data sekunder yang dikumpulkan meliputi data curah hujan harian tahun 2006 - 2016 yang diperoleh dari BMKG Kabupaten Bogor, peta tutupan lahan, dan masterplan dari Perumahan Dramaga Cantik 2 Kabupaten Bogor.

3. Pengolahan data

\subsection{Subcatchment}

Subcatchment merupakan daerah topografi dan sistem drainase yang mengalirkan langsung aliran permukaan menuju suatu titik aliran outlet. Pada subcatchment terdapat dua macam jenis area, yaitu impervious area (kedap air) dan pervious area (dapat dilalui air). Impervious area terdiri dari depression storage yang bergantung pada spesifikasi 
lahan yang ada (Tabel 2). Sementara pada pervious area nilai infiltrasi dihitung bergantung pada karakteristik tanah (Tabel 1 dan 3). Perhitungan nilai infiltrasi menggunakan metode Horton dapat dilihat pada persamaan (Rossman 2004).

$f p=f c+(f o-f c)^{-k t}$

Keterangan:

$\mathrm{fp}=$ angka infiltrasi dalam $\operatorname{tanah}(\mathrm{mm} / \mathrm{jam})$ fo $=$ harga infiltrasi maksimum $(\mathrm{mm} / \mathrm{jam})$ $\mathrm{fc}=$ harga infiltrasi minimum $(\mathrm{mm} / \mathrm{jam})$ $\mathrm{k}=$ koefisien penurunan head ( $1 / \mathrm{det})$ $\mathrm{t}=$ lama hujan (detik)

Tabel 1 Nilai infiltrasi minimum pada berbagai kondisi tanah

\begin{tabular}{|c|c|c|}
\hline Kelompok & Kondisi tanah & $\begin{array}{l}\text { Infiltrasi minimum } \\
\text { (mm jam) }\end{array}$ \\
\hline $\bar{A}$ & $\begin{array}{l}\text { Potensi limpasan yang rendah. Tanah } \\
\text { mempunyai tingkat infiltrasi yang } \\
\text { tinggi meskipun ketika tergenang dan } \\
\text { kedalaman genangan yang tingi, } \\
\text { pengeringan penyerapan baik unsur } \\
\text { pasir danbatuan }\end{array}$ & $>0.45$ \\
\hline B & $\begin{array}{l}\text { Tanah yang mempunyai tingkat } \\
\text { infiltrasi biasamedium ketika } \\
\text { tergenang dan mempunyai tingkat } \\
\text { kedalaman genangan medium, } \\
\text { pengeringan dengan keadaan biasa } \\
\text { didapat dari moderately fine to } \\
\text { moderately course }\end{array}$ & $0.30 \cdot 0.15$ \\
\hline $\mathrm{C}$ & $\begin{array}{l}\text { Tanah mempunyai tingkat infiltrasi } \\
\text { rendah jika galiran air dengan tingkat } \\
\text { tekstur bias ke tekstur baik. Contoh: } \\
\text { lempung. pasir bernalau }\end{array}$ & $0.15 \cdot 0.05$ \\
\hline D & $\begin{array}{l}\text { Potensi limpasan yang tinggi. Tanah } \\
\text { mempunyai tingkat infiltrasi rendah } \\
\text { ketika tergenang }\end{array}$ & $0.05 \cdot 0.00$ \\
\hline
\end{tabular}

Sumber: Rossman 2014

Tabel 2 Nilai Depression Storage

\begin{tabular}{lllc}
\hline No. & Kondisi tanah & Jenis tanah & $\begin{array}{c}\text { Infiltrasi maksimum } \\
\text { (mm/jam) }\end{array}$ \\
\hline 1 & Kering dengan & Tanah berpasir & 5 \\
& sedikit atau tidak & Tanah lempung & 3 \\
& ada tumbuhan & Tanah liat & 1 \\
2 & Kering dengan & Tanah berpasir & 10 \\
& banyak & Tanah lempung & 6 \\
& tumbuhan & Tanah liat & 2 \\
3 & Tanah lembab & Tanah berpasir & 1.25 \\
& & Tanah lempung & 1 \\
& & Tanah liat & 0.33 \\
\hline
\end{tabular}

Sumber: Rossman 2014
Tabel 3 Nilai infiltrasi maksimum pada berbagai kondisi tanah

\begin{tabular}{lc}
\hline Spesifikasi Lahan & $\begin{array}{c}\text { Depression Storage } \\
\text { (in) }\end{array}$ \\
\hline Imprevious Surface & $0.05-0.10$ \\
Lawns & $0.10-0.20$ \\
Pasture & 0.2 \\
Forest litter & 0.3 \\
\hline
\end{tabular}

Sumber: Rossman 2014

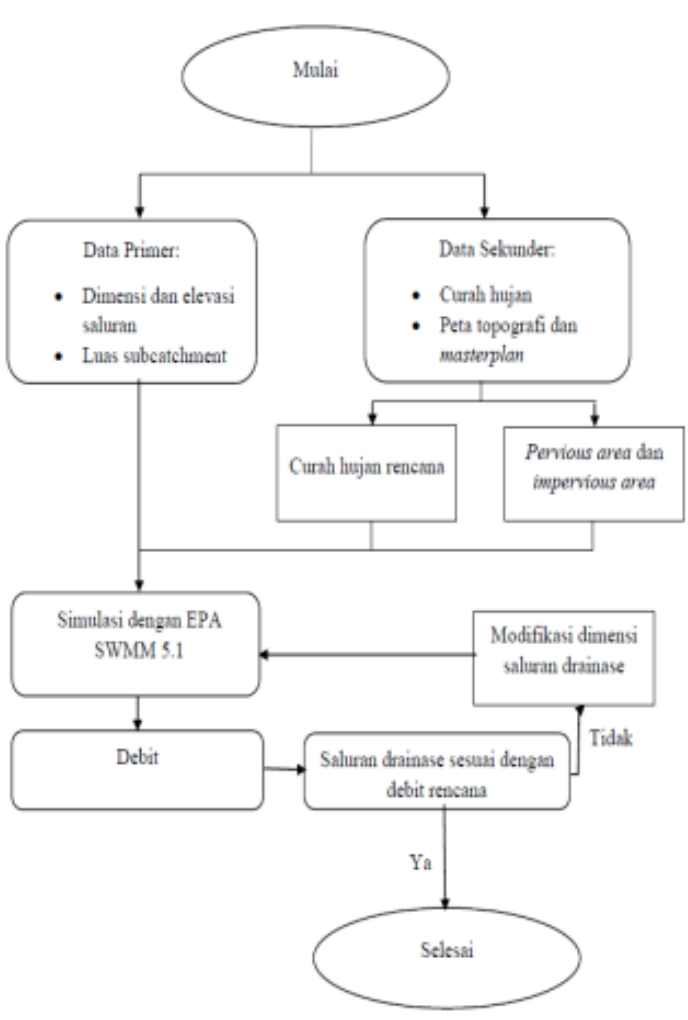

Gambar 1 Diagram alir penelitian

\subsection{Junction dan Outfall Node}

Junction node merupakan node node sistem drainase yang berfungsi untuk menggabungkan satu saluran dengan saluran lain. Outfall node adalah titik pemberhentian dari sistem drainase yang digunakan untuk menentukan batas hilir (downstream). Debit outflow dari limpasan subcatchment dihitung dengan persamaan Manning (2) (Chow 1997).

$$
Q=A V=\frac{A}{n} R^{2 / 3} S^{1 / 2}
$$


Keterangan:

$\mathrm{v}=$ kecepatan $(\mathrm{m} / \mathrm{det})$

$\mathrm{n}=$ koefisien Manning

$\mathrm{S}=$ kemiringan saluran

$\mathrm{A}=$ luas penampang saluran $\left(\mathrm{m}^{2}\right)$

$\mathrm{Q}=\operatorname{debit}\left(\mathrm{m}^{3} / \mathrm{det}\right)$

$\mathrm{R}=$ jari-jari hidrolik $(\mathrm{m})$

\subsection{Conduit}

Conduit adalah pipa atau saluran yang menyalurkan air dari satu node ke node lain. Bentuk melintang dari saluran dipilih dari beberapa macam bentuk standar yang disediakan EPA SWMM 5.1 Conduit memiliki nilai koefisien kekasaran manning $n$ yang berbeda menurut tipe saluran dan jenis bahan yang digunakan pada saluran.

\section{Analisis data}

4.1. Pervious area dan Impervious area Identifikasi daerah pervious dilakukan dengan melakukan survei di lapang untuk melihat daerah yang dapat menyerap air melalui infiltrasi (pervious) dan daerah yang tidak dapat melewatkan air (impervious). Kemudian dapat dihitung persentase luas daerah pervious dan impervious untuk setiap subcatchment, sebagai input data dalam subcatchment.

\subsection{Nilai Curah Hujan Rencana}

Nilai curah hujan rencana merupakan nilai input yang berupa time series. Analisis frekuensi untuk mendapatkan nilai curah hujan rencana dilakukan dengan menggunakan teori probability distribution, antara lain Distribusi Normal, Distribusi Log Normal, Distribusi Log Person III dan Distribusi Gumbel. Kemudian untuk pengujian kesesuaian distribusi yang digunakan dapat digunakan Uji SmirnovKolmogorof dan Uji Chi-Square (Anwar et al. 2014).

\subsection{Model EPA SWMM}

\subsubsection{Pembagian Subcatchment}

Langkah awal dalam penggunaan SWMM adalah pembagian subcatchment pada area penelitian. Pembagian tersebut sesuai dengan daerah tangkapan air (DTA) yang ditentukan berdasarkan pada elevasi lahan dan pergerakan limpasan ketika terjadi hujan.

4.3.2. Simulasi Respon Aliran pada Time Series

Simulasi respon aliran pada time series dilakukan untuk melihat respon debit aliran terhadap waktu berdasarkan sebaran curah hujan. Nilai yang dimasukkan adalah nilai sebaran curah hujan terhadap waktu dengan total nilai sesuai dengan curah hujan rencana yang dihasilkan analisis hidrologi.

4.3.3.Pembuatan Model Jaringan

Pembuatan model jaringan dilakukan berdasarkan sistem jaringan drainase yang ada di lapangan. Model jaringan ini terdiri dari subcatchment, junction node, outfall node, conduit, dan rain gauge. Setelah model jaringan selanjutnya dimasukkan semua nilai parameter yang dibutuhkan untuk semua properti tersebut.

\subsubsection{Simulasi model}

Simulasi ini dilakukan setelah model jaringan drainase dan semua parameter berhasil 
dimasukkan. Simulasi dapat dikatakan berhasil jika continuity error $<10 \%$. Dalam simulasi SWMM besarnya debit banjir dihitung dengan cara memodelkan suatu sistem drainase. Aliran permukaan atau limpasan permukaan terjadi ketika intensitas hujan yang jatuh di suatu daerah melebihi kapasitas infiltrasi. Selanjutnya limpasan terjadi (Q) akan mengalir melalui conduit atau saluran yang ada.

\subsubsection{Output SWMM}

Output dari simulasi ini meliputi runoff quantity continuity, flow routing continutiy, highest flow instability indexes, routing time step, subcatchment runoff, node depth, node inflow, node surcharge, node flooding, outfall loading, link flow, dan conduit surcharge yang disajikan dalam laporan statistik simulasi rancangan yang divisualisasikan dalam jaringan saluran drainase hasil output dari simulasi, profil aliran dari beberapa saluran utama dan yang diketahui tergenang, dan grafik aliran yang terjadi pada saluran.

\section{HASIL DAN PEMBAHASAN}

\section{Keadaan Umum Lokasi Penelitian}

Lokasi penelitian berada di Perumahan Dramaga Cantik 2, Bogor, Jawa Barat, yang terletak di kelurahan Sukatani, Dramaga, Bogor. Luas keseluruhan Perumahann Dramaga Cantik 2 sebesar $6.795 \mathrm{Ha}$ dengan kondisi tata guna lahan didominasi oleh pemukiman dan pengerasan jalan oleh aspal. Perumahan Dramaga Cantik memiliki elevasi 199-201 mdpl dengan total rumah yang telah terbangun mencapai 98 rumah yang dibagi menjadi beberapa subcatchment. Berdasarkan pengamatan langsung di lapangan, kondisi saluran drainase di blok Perumahan Dramaga Cantik 2 sebagian besar terlihat baik. Namun, di beberapa ruas kondisi saluran terlihat tertutup oleh tumbuhan liar dan timbunan galian sehingga terdapat sedimentasi, hal ini dikarenakan sedang berlangsungnya pembangunan di Perumahan Dramaga Cantik 2.

\section{Analisis Curah Hujan Rencana}

Analisis curah hujan rencana dilakukan menggunakan data curah hujan harian dari tahun 2005 hingga 2014 milik Stasiun Badan Meteorologi, Klimatologi, dan Geofisika (BMKG) Dramaga, Bogor. Curah hujan rencana dihitung berdasarkan data curah hujan harian maksimum selama 10 tahun yang dapat dilihat pada Tabel 4 .

\begin{tabular}{cccc}
\multicolumn{4}{c}{ Tabel 4 Data curah hujan harian maksimum selama 10 tahun } \\
\hline Tahun & $\begin{array}{c}\text { CH maks } \\
\text { (mm) }\end{array}$ & Tahun & $\begin{array}{c}\text { CH maks } \\
\text { (mm) }\end{array}$ \\
\hline 2004 & 126.5 & 2009 & 144.5 \\
2005 & 136.4 & 2010 & 97.6 \\
2006 & 155.5 & 2011 & 123.1 \\
2007 & 104.5 & 2012 & 136.8 \\
2008 & 115.1 & 2013 & 169.1 \\
\hline
\end{tabular}

Berdasarkan Tabel 4, dapat dihitung nilai hujan rencana dengan menggunakan metode distribusi probabilitas. Analisis frekuensi dilakukan dengan menggunakan metode distribusi probabilitas yakni distribusi Normal, distribusi Log Normal, distribusi Log Pearson III, dan distribusi Gumbel (Triatmodjo 2010). Kala ulang (return period) yang digunakan untuk menghitung 
nilai hujan rencana yaitu $2,5,10,25$, dan 50 tahun. Return period adalah waktu perkiraan di mana hujan dengan suatu besaran tertentu akan disamai atau dilampaui. Hasil analisis frekuensi curah hujan rencana dapat dilihat pada Tabel 5.

\begin{tabular}{ccccc}
\multicolumn{5}{c}{ Tabel 5 Hasil analisa curah hujan rencena (mm) } \\
\hline $\begin{array}{c}\text { Periode } \\
\text { (tahun) }\end{array}$ & normal & log normal & log pearson III & Gumbel \\
\hline 2 & 130.910 & 129.200 & 129.772 & 127.903 \\
5 & 149.589 & 149.245 & 149.744 & 154.448 \\
10 & 159.373 & 160.957 & 157.733 & 172.025 \\
25 & 168.934 & 173.290 & 165.236 & 194.231 \\
50 & 176.495 & 183.707 & 169.491 & 210.704 \\
\hline
\end{tabular}

Hasil perhitungan nilai curah hujan rencana dari setiap metodenya memiliki nilai yang berbeda sehingga harus diuji kesesuaiannya dengan sifat masingmasing jenis distribusi yang dilakukan dengan melakukan tinjauan terhadap syarat batas parameter statistik tiap distribusi. Penentuan tipe distribusi dapat dilihat dari parameter-parameter statistik data pengamatan lapangan yaitu nilai $\mathrm{Cs}$ dan Ck.

Tabel 6 Perbandingan parameter distribusis probabilitas

\begin{tabular}{|c|c|c|c|c|}
\hline \multirow{2}{*}{ Jenis distribusi } & \multirow{2}{*}{ Cs } & \multirow{2}{*}{$\mathrm{Ck}$} & \multicolumn{2}{|c|}{ Syarat } \\
\hline & & & Cs & $\mathrm{Ck}$ \\
\hline Gumbel & 0.1712 & 3.5003 & $C_{s}=1.14$ & $\mathrm{Ck}=5.4$ \\
\hline Normal & 0.1712 & 3.5003 & $\operatorname{cs} \approx 0$ & $\mathrm{CK} \approx 3$ \\
\hline Log normal & 0.1712 & 3.5003 & $C_{s}=0.43$ & $\mathrm{Ck}=3.33$ \\
\hline Log pearson III & 0.1712 & 3.5003 & \multicolumn{2}{|c|}{ selain dari nilai di atas } \\
\hline
\end{tabular}

Berdasarkan Tabel 6, nilai yang memenuhi syarat yaitu jenis distribusi Log Pearson III. Selanjutnya dilakukan uji kecocokan dengan uji Chi Kuadrat yang dimaksudkan untuk mengetahui apakah pemilihan metode distribusi frekuensi yang digunakan dapat diterima atau ditolak. Nilai distribusi yang digunakan untuk pengujian Chi Kuadrat yaitu distribusi Log Pearson III. Hasil pengujian uji Chi Kuadrat dapat dilihat pada Tabel 7.

Tabel 7 Hasil perhitungan uji Chi Kuadrat distribusi Log Person III

\begin{tabular}{cccccc}
\hline Kelas & Interval & Of & Ef & Of-Ef & (Of-Ef)2 Ef \\
\hline 1 & $>2.1902$ & 2 & 2 & -1 & 0 \\
2 & $2.1251 \cdot 2.1902$ & 3 & 2 & 2 & 0.5 \\
3 & $2.0795 \cdot 2.1251$ & 2 & 2 & 0 & 0 \\
4 & $2.0364 \cdot 2.0795$ & 1 & 2 & -1 & 0,5 \\
5 & $<2.0364$ & 2 & 2 & 0 & 0 \\
\hline$\sum$ & & 10 & 10 & 0 & 1 \\
\hline
\end{tabular}

Data pada Tabel 7 menunjukan nilai ${ }^{2}$ yang didapatkan sebesar 1 . Hal ini menunjukkan pengujian untuk distribusi Log Pearson III dapat diterima karena nilai ${ }^{2}$ perhitungan lebih kecil dari ${ }^{2}$ pada tabel uji Chi Kuadrat yang nilainya 5.991. Nilai yang digunakan merujuk pada Tabel 5 yaitu 129.772 nilai tersebut diambil karena menurut KEMENPU untuk analisis saluran drainase saluran pada daerah tangkapan air yang luasnya kurang dari 10 ha digunakan periode ulang 2 tahun. Berdasarkan hasil curah hujan maksimum yang didapat lalu didistribusikan berdasarkan wilayah Kota Bogor dengan persentase distribusi setiap jam sebesar $0 \%, 38 \%, 28 \%, 11 \%, 14 \%$ dan $9 \%$ (Priambodo 2004). Adapun hasil distribusi hujan rencana di Kota Bogor ditunjukkan pada Tabel 8.

\begin{tabular}{|c|c|c|c|c|}
\hline \multicolumn{5}{|c|}{ istribulusi } \\
\hline Waktu (jam ke.) & 1 & 2 & 3 & 4 \\
\hline Distribulisiniman (\%) & 38 & 28 & 11 & 14 \\
\hline
\end{tabular}

Berdasarkan Tabel 8 terlihat bahwa hasil distribusi hujan rencana di kota Bogor mengalami fluktuasi. Hal ini 
disesabkan distribusi hujan yang digunakan juga mengalami fluktuasi.

\section{Pembagian Subcatchment}

Berdasarkan pengamatan di lapangan diketahui bahwa sistem drainase sudah cukup baik namun ada beberapa lokasi yang dimensinya kurang memadai dan ada pula yang terlalu boros. Pemodelan jaringan merupakan hal utama dalam simulasi SWMM. Untuk itulah sistem saluran drainase dimodelkan ke dalam SWMM menjadi beberapa bagian.

Karakteristik saluran drainase yang dimasukkan ke dalam pemodelan adalah junction, conduit, subcatchment area dan outfall. Dalam pemodelan ini perumahan Dramaga Cantik 2 dibagi kedalam 17 subcatchment yang pembagiannya didasarkan pada elevasi lahan dan arah pergerakan limpasan saat terjadinya hujan. Pemodelan merupakan data lahan pervious dan impervious asumsi seluruh rumah telah terbangun. Karakteristik subcatchment dapat dilihat pada Lampiran 3.

\section{Pemodelan Jaringan Drainase}

Berdasarkan hasil observasi lapangan saluran drainase dapat dimodelkan pada software EPA SWMM 5.1. Adapun komponen kerangka awal hidrolika yang digunakan adalah junction, conduit, dan outfall nodes. Pada pemodelan yang dilakukan, junction bernotasi $\mathrm{J}$, counduit bernotasi C, dan outfall bernotasi O. Pada area tersebut terdapat 38 conduit, 39 junction dan 2 outfalls nodes. Outlet tersebut mengalir menuju saluran drainase perumahan Dramaga Cantik. Kondisi jaringan saluran drainase sudah baik dengan Hasil pemodelan jaringan drainase terdapat

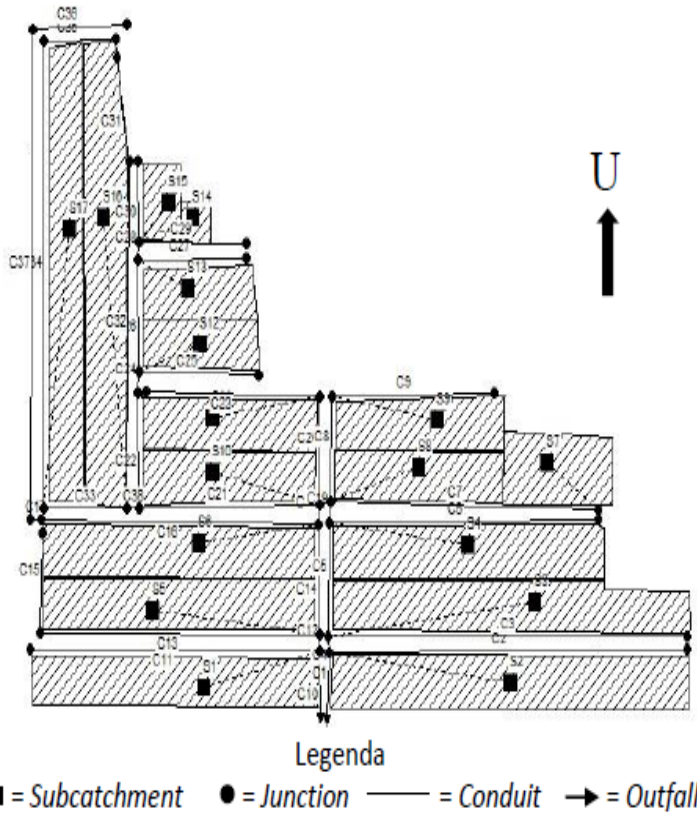

Gambar 2 Pemodelan jaringan drainase

\section{Simulasi Model}

Simulasi kemudian dijalankan setelah jaringan dimodelkan. Hasil simulasi menunjukkan kualitas yang baik dengan nilai continuity error surface runoff sebesar $0.53 \%$ dan nilai continuity error flow routing hasil simulasi kedua area sebesar $0.02 \%$. Hal ini menunjukkan terjadinya limpasan pada saluran drainase. Berdasarkan hasil simulasi curah hujan sebanyak $129.772 \mathrm{~mm}$, sebagian diserap oleh daerah tangkapan air (subcatchment) dan sebagian mengalir sebagai limpasan.

Hasil simulasi pada Gambar 3 menunjukkan pada jam ke-1 didapatkan pada conduit 24 dan terjadi limpasan yang ditunjukkan dengan warna merah. Hal ini dikarenakan dimensi saluran yang kurang memadai untuk menampung aliran dari saluran sebelumnya. Adapun node junction 25 hingga junction 21 menunjukkan profil aliran pada conduit 24 saat terjadi limpasan (Gambar 4). 


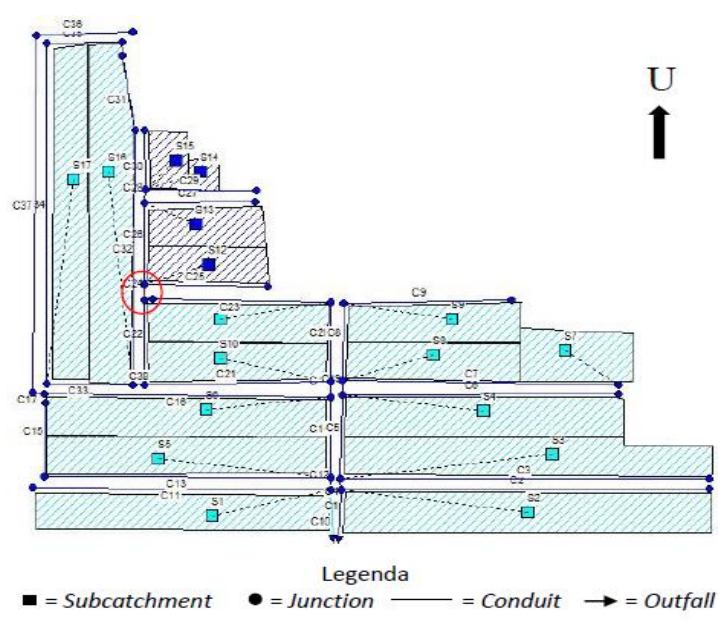

Gambar 3 Hasil simulasi jaringan drainase terhadap waktu

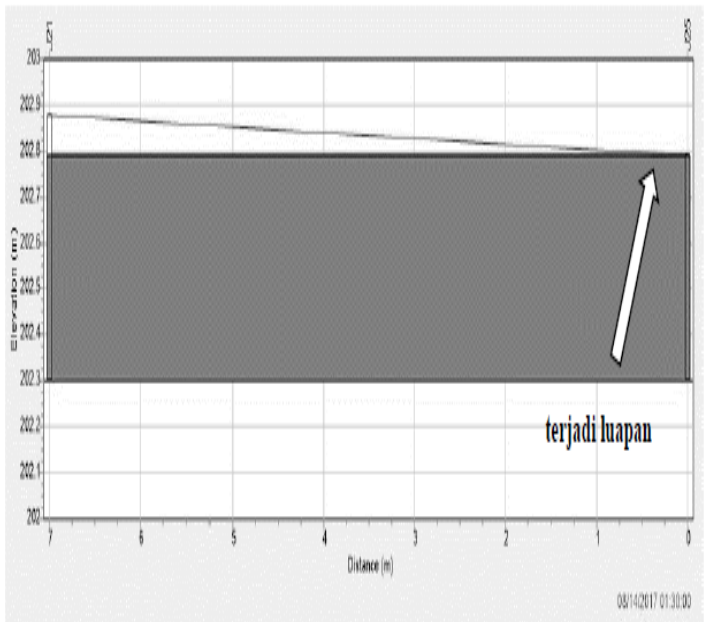

Gambar 4 Profil aliran C24

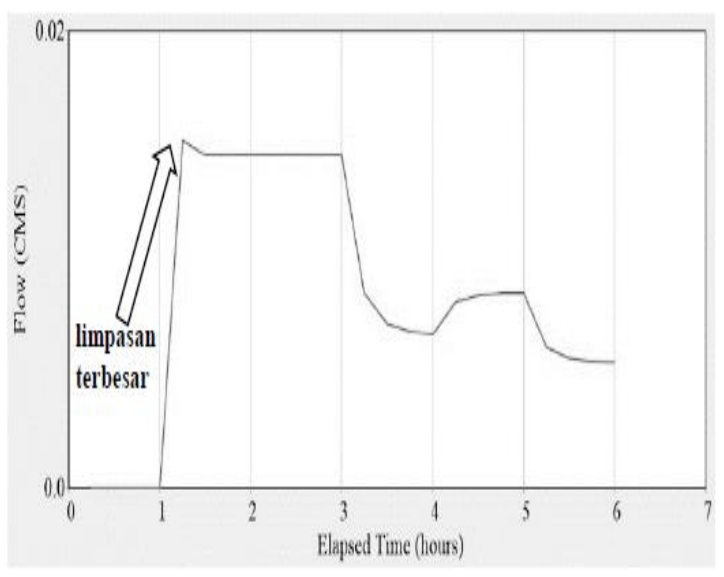

Gambar 5 Besaran limpasan terhadap waktu

Berdasarkan Gambar 5 diketahui bahwa pada C24 sebagian saluran terisi penuh oleh limpasan yang dikarenakan kurang memadainya dimensi saluran C24. Berdasarkan hasil simulasi didapatkan bahwa limpasan yang terbesar terjadi pada jam ke-1 karena hasil distribusi hujan rencana yang terbesar terjadi pada waktu tersebut. Adapun besaran limpasan terhadap waktu pada saluran C24 akan ditunjukkan pada Gambar 5.

Berdasarkan Gambar 5 diketahui bahwa besaran limpasan yang terbesar terjadi pada jam ke-1 pada saluran yang meluap yang dikarenakan pada hasil distribusi hujan rencana terbesar terjadi pada jam ke-1. Hasil tersebut menunjukkan pada jam ke 1 saluran C24 memiliki debit limpasan yang besar. Setelah itu besar limpasan kembali menurun terhadap waktu. Kemudian dilakukan upaya perbaikan dengan memodifikasi dimensi saluran drainase C24 yang mengalami limpasan. Setelah dilakukan trial and error untuk penambahan dimensi, dilakukan penambahkan lebar pada saluran drainase C24 sebesar $10 \mathrm{~cm}$ dari $0.32 \mathrm{~m}$ menjadi $0.42 \mathrm{~m}$. Adapun hasil simulasi jaringan drainase pada EPA SWMM setelah mengalami modifikasi ditunjukkan pada Gambar 6 dan profil aliran J21 pada Gambar 7.

Berdasarkan Gambar 7, terlihat bahwa saluran sudah tidak meluap meskipun dengan kondisi hampir penuh. Hal ini dikarenakan pada hasil simulasi EPA SWMM 5.1 saluran C24 berubah warna dari merah menjadi kuning (Gambar 7). Profil aliran J21 hingga O2 setelah saluran $\mathrm{C} 24$ diperbaiki dapat dilihat pada Gambar 8 . 


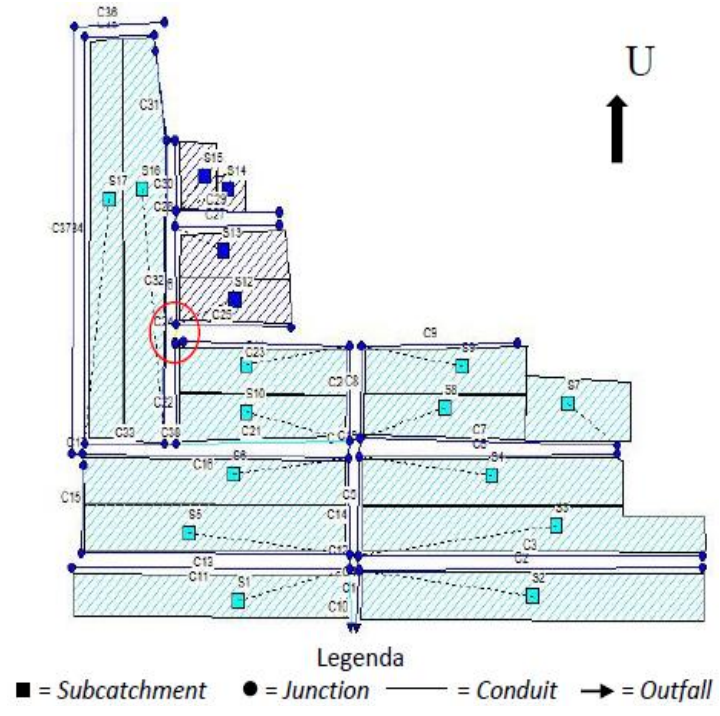

Gambar 6 Hasil modifikasi simulasi jaringan drainase

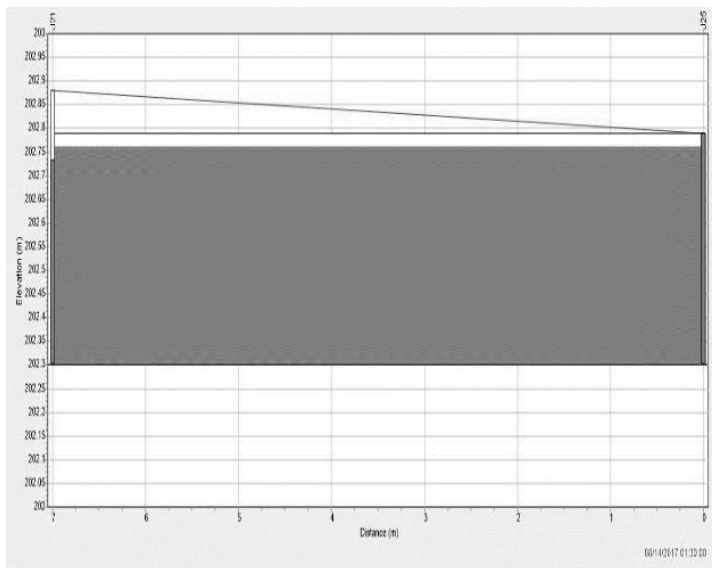

Gambar 7 Profil aliran C24 setelah diperbaiki

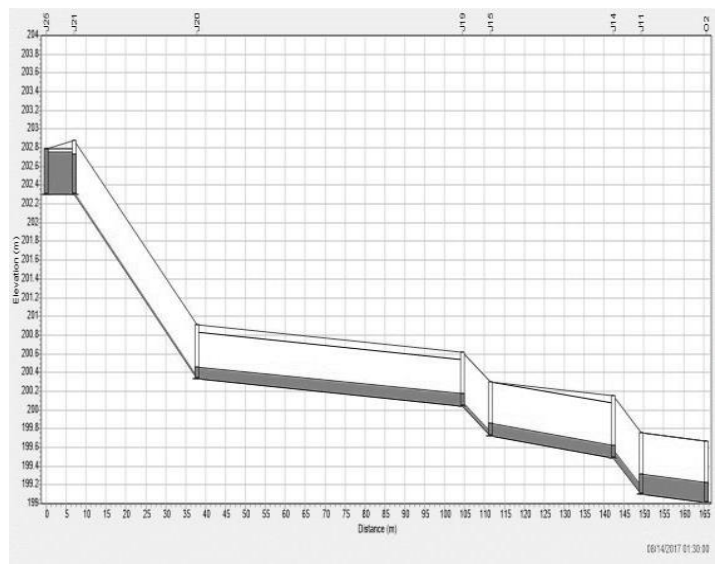

Gambar 8 Profil aliran J21 hingga O2 setelah diperbaiki
Perubahan dimensi saluran C24 dapat menyebabkan limpasan pada saluran berikutnya jika dimensinya lebih kecil dari saluran C24, namun pada Gambar 9 terlihat bahwa hasil perbaikan tidak menyebabkan limpasan pada saluran dari node J21 hingga $\mathrm{O} 2$ dikarenakan saluran tersebut sudah memiliki dimensi yang lebih besar dari saluran C24 yang sudah di modifikasi. Adapun estimasi rencana angggaran perbaikan pada saluran drainase didapatkan sebesar $\mathrm{Rp}$ 2,368,393.00.

Selain modifikasi saluran, terdapat alternatif lain untuk mencegah terjadinya luapan air yaitu dengan meningkatkan laju infiltrasi tanah, untuk itu ada beberapa pilihan seperti pembuatan sumur resapan, kolam retensi maupun biopori. Pembuatan sumur resapan dan kolam retensi memerlukan data kedalaman tanah minimum di setiap subcatchment (PermenPU 2014). Karena keterbatasan data yang dimiliki, pembuatan biopori merupakan cara alternatif yang dapat digunakan jika perbaikan saluran tidak memungkinkan. Untuk membuat lubang biopori dengan curah hujan pada jam ke-1 sebesar $49 \mathrm{~mm}$, diperlukan sebanyak 175 lubang biopori dengan estimasi biaya sebesar Rp 400,000.00 dengan asumsi pembuatan biopori menggunakan bor tanah (Hilwatullisan 2010).

\section{KESIMPULAN}

Berdasarkan hasil simulasi dengan EPA SWMM 5.1. kapasitas saluran drainase perumahan Dramaga Cantik 2 sudah mencukupi namun terjadi limpasan pada saluran C24. Hal ini disebabkan saluran tidak mampu menampung aliran dari saluran sebelumya. Untuk itu sebaiknya dilakukan modifikasi dimensi saluran menjadi lebar $0.42 \mathrm{~m}$ dengan 
biaya perbaikan saluran diestimasikan sebesar Rp 2,368,393.00.

\section{SARAN}

Sebaiknya dilakukan perbaikan agar tidak terjadi limpasan dikemudian hari pada saluran $\mathrm{C} 24$, jika modifikasi tidak memungkinkan dapat menggunakan biopori sebagai alternatif namun perlu memerhatikan penimbunan sampah organik di tiap lubang biopori agar infiltrasi tetap terjaga.

\section{DAFTAR PUSTAKA}

Anwar, Pudoyono, Ruslin M, Suharyanto A, Suroso, Wicaksono DH. 2014. Evaluasi dan Perencanaan Ulang Saluran Drainase pada Kawasan Perumahan Sawojajar Kecamatan Kedungkandang Kota Malang. Jurnal Rekayasa Sipil. 8(3): 207

Arsana A, Dewi IA, Suputra O. 2013. Analisis Kapasitas Saluran Drainase Sekunder dan Penanganan Banjir di Jl Gatot Subroto Denpasar. Jurnal Ilmiah Elektronik Infrastruktur Teknik Sipil 2(2): 42

Bisri M, Djakfar L, Kusumadewi DA. 2012. Arahan Spasial Teknologi Drainase untuk Mereduksi Genangan di Sub Daerah Aliran Sungai Watu Bagian Hilir. Jurnal Teknik Perairan. 3(2): 260

Burhanudin H, Nurhapni. 2010. Kajian Pembangunan Sistem Drainase Berwawasan Lingkungan di Kawasan Perumahan [skripsi]. Bandung (ID): Fakultas Teknik Universitas Islam Bandung.

Chow VT. 1959. Open Channel Hydraulics. New York (US): McGraw-Hill.

Darsono S, Sugiyanto, Wibowo A, Widyatmoko MY. 2014.
Perencanaan Saluran Drainase Kawasan Oasis PT. Djarum Kudus di Kabupaten Kudus. Jurnal Karya Teknik Sipil. 3(1): 84

Fairizi D. 2015. Analisis dan Evaluasi Saluran Drainase pada Kawasan Perumnas Talang Kelapa di Subdas Lambirado Kota Palembang. Jurnal Teknik Sipil dan Lingkungan. 3(1): 755.

Hilwatullisan. 2010. Lubang Resapan Biopori (LRB) Pengertian dan Cara Membuatnya dilingkungan kita [skripsi]. Palembang (ID) : Jurusan Teknik Kimia Politeknik Negeri Sriwijaya.

Ihsan M, Setiawan BI. 2014. Analisis Hujan, Debit Puncak Limpasan, dan Volume Genangan di Sekitar Gedung Graha Widya WisudaFEMA, Kampus IPB Dramaga Bogor. Jurnal Keteknikan Pertanian. 1(1):1-11.

Isfandari DT, Reini SI. 2014. Analisis

Sistem Drainase di Kawasan Pemukiman pada Sub DAS Aur Palembang (Studi Kasus: Pemukiman 9/10 Ulu). Jurnal Teknik Sipil dan Lingkungan. Vol 2(1).

Jang JH, Park CK, Park HS. 2006. Analysis of the effect of sewer system on urban stream using PCSWMM based on GIS. Jurnal Korean Soc. Water Quality. 22 (6): 982-990.

[KemenPU] Kementerian Pekerjaan Umum. 2014. Pengelolaan Air Hujan pada Bangunan Gedung dan Persilnya. Peraturan Menteri Pekerjaan Umum nomor 12 tahun 2014. Jakarta (ID): Kementerian Pekerjaan Umum

Mulyono D. 2014. Analisis Karakteristik Curah Hujan di Wilayah Kabupaten 
Garut Selatan. Jurnal Konstruksi.

13(1): 2

Priambodo S. 2004. Karakteristik Hujan

di Beberapa Stasiun Hujan di

Wilayah DKI Jakarta [tesis].

Yogyakarta (ID): Universitas

Gadjah Mada.

Rossman L. 2004. Storm Water

Management Model User's Manual

Version 5.0.Cincinnati. Washington

(US): EPA United Stated Environmental Agency.

Suripin M. 2003. Sistem Drainase

Perkotaan yang Berkelanjutan.

Yogyakarta (ID): ANDI.

Triatmodjo B. 2010. Hidrologi Terapan.

Yogyakarta (ID): Beta Offset.

Wesli. 2008. Drainase perkotaan.

Yogyakarta (ID): Graha Ilmu.

Widiati A. 2008. Aplikasi Manajemen

Risiko Bencana Alam dalam

Penataan Ruang Kabupaten Nabire.

Jurnal Sains dan Teknologi

Indonesia. 10(1): 7-15.

Wilson EM. 1990. Engineering Hydrology.

London (UK): Mac Milan

Education 
JSIL | Qintana dkk. : Analisis Kapasitas Sistem Saluran Drainase Di Perumahan Dramaga Cantik Z Kabupaten Bagar 